\title{
BMJ Open Facilitators and barriers to the self- management of COPD: a qualitative study from rural Nepal
}

\author{
Uday Narayan Yadav (D) ,1,2 Jane Lloyd, ${ }^{2}$ Hassan Hosseinzadeh, ${ }^{3}$ \\ Kedar Prasad Baral, ${ }^{4}$ Sagar Dahal, ${ }^{5}$ Narendra Bhatta, ${ }^{6}$ Mark Fort Harris (1) ${ }^{2}$
}

To cite: Yadav UN, Lloyd J, Hosseinzadeh $\mathrm{H}$, et al. Facilitators and barriers to the self-management of COPD: a qualitative study from rural Nepal. BMJ Open 2020;10:e035700. doi:10.1136/ bmjopen-2019-035700

- Prepublication history for this paper is available online. To view these files, please visit the journal online (http://dx.doi. org/10.1136/bmjopen-2019035700).

Received 12 November 2019 Revised 27 January 2020 Accepted 13 February 2020

Check for updates

(c) Author(s) (or their employer(s)) 2020. Re-use permitted under CC BY-NC. No commercial re-use. See rights and permissions. Published by BMJ.

For numbered affiliations see end of article.

Correspondence to Uday Narayan Yadav; unyadav1@gmail.com

\section{ABSTRACT}

Objective To understand the facilitators and barriers to the self-management of chronic obstructive pulmonary disease (COPD) in rural Nepal.

Settings Community and primary care centres in rural Nepal.

Participants A total of 14 participants (10 people with COPD and 4 health care providers) were interviewed.

Primary and secondary outcome measure(s) People with COPD and healthcare provider's experience of COPD self-management in rural Nepal.

Results Facilitators and barriers affecting COPD selfmanagement in Nepal operated at the patient-family, community and service provider levels. People with COPD were found to have a limited understanding of COPD and medications. Some participants reported receiving inadequate family support and described poor emotional health. At the community level, widespread use of complementary and alternative treatment was found to be driven by social networks and was used instead of western medicine. There were limited quality controls in place to monitor the safe use of alternative treatment. While a number of service level factors were identified by all participants, the pertinent concerns were the levels of trust and respect between doctors and their patients. Service level factors included patients' demands for doctor time and attention, limited confidence of people with COPD in communicating confidently and openly with their doctor, limited skills and expertise of the doctors in promoting behavioural change, frustration with doctors prescribing too many medicines and the length of time to diagnose the disease. These service level factors were underpinned by resource constraints operating in rural areas. These included inadequate infrastructure and resources, limited skills of primary level providers and lack of educational materials for COPD.

Conclusions The study findings suggest the need for a more integrated model of care with multiple strategies targeting all three levels in order to improve the selfmanagement practices among people with COPD.

\section{INTRODUCTION}

Chronic obstructive pulmonary disease (COPD) is a global public health problem ${ }^{1}$ with a large potential burden on patients, society and the healthcare system. ${ }^{2}$ WHO projected COPD as the third leading cause

\section{Strengths and limitations of this study}

- This qualitative study captured the perspective of both people with chronic obstructive pulmonary disease (COPD) and primary level healthcare providers to identify factors influencing self-management among patients with COPD.

- It is a unique study of COPD self-management in rural Nepal with people with low income and poor educational attainment.

- The included themes were consistent with those in the COPD self-management literature that has not previously demonstrated in rural or any other setting of Nepal and findings of this study have a wider implication at the local level in rural Nepal.

- The in-depth interviews were conducted by a researcher in the local language that provided insights and access to the participants and a solid ethical foundation for conducting research in low-income andmiddle-income countries.

- The study used purposive sampling which may have led to a sampling bias based on participant's ability to share information.

of death by $2030 .{ }^{3}$ More than $90 \%$ of COPDrelated deaths occur in low-income and middle-income countries (LMICs), ${ }^{4}$ where a large proportion of patients with COPD remain undiagnosed and untreated in their communities. Recently published findings from Nepal showed a COPD prevalence of $11.7 \%$, and COPD had the highest prevalence among selected non-communicable diseases (NCDs). ${ }^{5}$ The increasing number of cases of COPD is a burden to the country's health system and also impacts on the quality of life of patients and their families and carers. The management of COPD is more challenging in LMICs like Nepal, where there is a lack of trained healthcare providers and limited facilities for diagnosing and managing COPD at the primary care level.

Self-management is increasingly recognised as an important strategy in policy. By engaging patients, families/carers, communities and 
health professionals, patients can be activated to access care and manage their conditions. ${ }^{6-8}$ Evidence has shown that several barriers, such as poor health literacy, ${ }^{9-11}$ patients empowerment/confidence ${ }^{9}{ }^{12}$ comorbidities, ${ }^{1314}$ social support, ${ }^{1014}$ depression and anxiety, ${ }^{1014}$ lack of promotion of behaviour change by practitioners, ${ }^{10} 15$ lack of services for COPD at the primary healthcare (PHC) level ${ }^{14}{ }^{16}$ inadequate skills of healthcare providers in diagnosing and managing chronic disease ${ }^{1416}$ often block the active engagement of patients in self-management practices. Effective and sustained self-management can be only achieved if the underlying factors are addressed at patient and family, social and service levels with adequate focus on health literacy and patient empowerment. ${ }^{9}$

While the facilitators and barriers affecting selfmanagement, practices have been explored in various settings, there is no research on patients' and providers' perspectives exploring the facilitators and barriers to COPD self-management in rural Nepal. Therefore, this study aimed to understand the facilitators and barriers affecting COPD self-management.

\section{METHODS \\ Design}

This study used an inductive approach ${ }^{17}$ to guide the analysis of data. The study was undertaken with a interpretivist epistemological view. ${ }^{18}$ We explored the barriers and facilitators to self-management practices in a rural setting. Participants shared with the interviewer, their experience of diagnosis and management of COPD in the natural setting.

\section{Participants and setting}

We recruited 10 people with COPD from community and 4 primary level healthcare providers (HCPs) working in a primary healthcare centre (PHCC) or health post (HP) in two rural municipalities of Sunsari, district of Nepal. The sampling and recruitment process of the study participants is described as follows:

\section{People with COPD}

i. The sampling frame for people with COPD that designed for our quantitative survey was used for this study. The sampling frame was constructed by collecting the details of people with COPD from the PHC and also through the community mapping of COPD cases (to include the people with COPD who access services in private health facility) with the help of female community health volunteers. Information on COPD cases were also obtained from morning tea catcher point (favourite place for the locals to chitchat in the morning hours).

ii. In the process of the quantitative survey at the doorsteps of the people with COPD, the lead author invited the people with COPD to participate in in-depth interviews to share their experiences, opinions and time. iii. The people with COPD who showed interest in participating in the in-depth interviews were selected purposively according to gender, ethnicity (Higher caste, Indigenous, Dalit and Madeshi) and education status (uneducated, educated and higher education) as a representative of the study area.

\section{Healthcare providers}

i. All the HCPs from PHCC and HPs were invited to participate in the study via phone, and those who showed their interest in sharing experiences, opinions and time were selected and interviewed.

\section{Patient and public involvement}

Patients and the public were not involved in the conception of this study, development of the research question, interpretation of the results or manuscript writing. The findings of this study were disseminated to the people with COPD and other participants in a co-design workshop held at Gadhi Rural Municipality in July 2019.

\section{Interviews/data collection}

Fieldwork was conducted between September 2018 and December 2018. In-depth interviews were conducted using semi-structured interview guides prepared separately for people with COPD and HCPs. We adopted purposive sampling to select the study participants, and data collection was continued until the saturation point was reached. To decide the saturation point, the interviewer prepared the interview summary of each interview and checked if new participants generated any new ideas.

The lead author, who is a PhD student, knows the local language and conducted all the interviews. People with COPD were interviewed at their home, where family members were asked to leave the participants with the interviewer so that participants could unveil their stories in confidence. The interview with HCPs was conducted in a healthcare centre. The author belonged to the same geographic region (plain region of southern Nepal) as the participants. In this region, two languages are mainly spoken in the community by the Indigenous and different ethnic groups including, Dalit, and Madeshi and higher caste. Belonging to the same geographical location, and speaking both of the two languages spoken by people with COPD enabled the lead researcher to recruit participants and it also made it more open and comfortable for participants to share their stories and views.

In addition to interviews, field notes were used to record postinterview conversations and observations.

\section{Data coding and analysis}

The interviews were audio-recorded in local (Maithili/ Tharu language was used for people with COPD and Nepali for HCPs) language and transcribed; they were then translated into English by the lead author. The four random interviews were cross-checked by bilingual experts in order to ensure the reliability of transcription. The data were analysed using the thematic analysis, as suggested by Braun and Clarke. ${ }^{17}$ The method by 


\begin{tabular}{|c|c|c|}
\hline ID no. & Gender & Age (in years) \\
\hline 001 & Female & $50-55$ \\
\hline 002 & Female & $50-55$ \\
\hline 003 & Male & $50-55$ \\
\hline 004 & Female & $70-75$ \\
\hline 005 & Female & $60-65$ \\
\hline 006 & Female & $60-65$ \\
\hline 007 & Female & $70-75$ \\
\hline 008 & Male & $70-75$ \\
\hline 009 & Female & $50-55$ \\
\hline 0010 & Male & $75-80$ \\
\hline
\end{tabular}

Braun and Clarke considers six phases in thematic analysis: familiarisation with the data including transcribing, generating initial codes, searching for themes, reviewing the themes, defining and naming the themes and writing a research report. NVivo software (V.12:00) was used to organise the data and facilitate the coding process.

\section{RESULTS}

The demographic profiles of participants are presented in tables 1 and 2. Eight broad themes emerged from the interviews of patients and HCPs. Themes derived from the people with COPD and providers' perspectives have been organised into three categories: people with COPD/family, community setting and service level factors (figure 1), which is consistent with the socioecological model. ${ }^{19}$ Verbatim quotes for each theme and subthemes are provided in table 3 .

\section{People with COPD and family level facilitators and barriers}

The two main subthemes at the patient and family level were family support and health literacy.
Family support

People with COPD require ongoing care throughout life, and they require family support in their daily activities. This includes providing information about the disease, looking after their dietary needs, arranging visits to the doctor and providing translation and information support during the clinical interactions, support with medications and lifestyle changes (exercise, smoking cessation and eating a healthy diet). Family members have the potential to play a great role in improving their quality of life of people with COPD. During the interview process, all people with COPD expressed some expectations of family support and care, such as assisting with taking medications.

Only three patients felt adequately supported by their family members. One belonged to a higher caste educated family and, two from educated Madeshi and Indigenous community families. The researcher noted that the people whose family members were literate received more family support and that these people tended to be from a higher caste. The opposite was true of those from the illiterate unprivileged ethnic groups (Indigenous/ Dalits or the Madeshi community).

Some patients felt let down and inadequately cared for by their family members. Most people with COPD who indicated that they lacked family support, reported grievances. These included not assisting them to see the doctor at the requested time, inadequate financial support to purchase medicine and lack of support in daily activities such as not getting food on time or help in pumping water for a bath. However, participants did not complain about the quality of food. Two people with COPD were dependent on their daughters-in-law, who were in charge of cooking. When family members were busy with household or agriculture activities, they did not prioritise cooking food for themselves or the sick/older people.

\section{Table 2 Profile of healthcare providers}

\begin{tabular}{ll}
\hline IDI & Profile of healthcare providers \\
\hline IMO, M30-35 & $\begin{array}{l}\text { The medical officer was an MBBS graduate (a medical doctor), responsible for managing cases at } \\
\text { the PHCC. At the time of the interview, the doctor had been working at the clinic for } 3 \text { years. }\end{array}$ \\
IIN, F25-30 & $\begin{array}{l}\text { An interviewed nurse was a BSC nursing graduate. She was working with PHC for }>2 \text { years and was } \\
\text { responsible for delivering preventive and curative services to the patients. }\end{array}$ \\
IIIAWH, M30-40 & $\begin{array}{l}\text { In Nepal, a mid-level health worker (auxiliary health worker or health assistant) is responsible for } \\
\text { managing the health post. Mid-level health workers have some clinical responsibilities such as } \\
\text { diagnosing and treating common conditions and referring complex cases to PHCC/secondary or } \\
\text { tertiary health centres. At the time of the interview, the senior auxiliary health worker had }>15 \text { years' } \\
\text { experience managing the health post and the conditions under his practice. } \\
\text { FCHV, also known as 'female volunteer', are frontline pillars of a community-based health } \\
\text { programme in Nepal. They are responsible for educating and delivering health promotion } \\
\text { programme at the community level and recording and reporting of data in the community. At the } \\
\text { time of interview, the FCHV had secondary level school education (10 years of school education) } \\
\text { and } 10 \text { years' experience in a community-based activity. }\end{array}$ \\
\hline
\end{tabular}

FCHV, female community health volunteers; HP, health post; PHC, primary healthcare; PHCC, primary healthcare centre. 


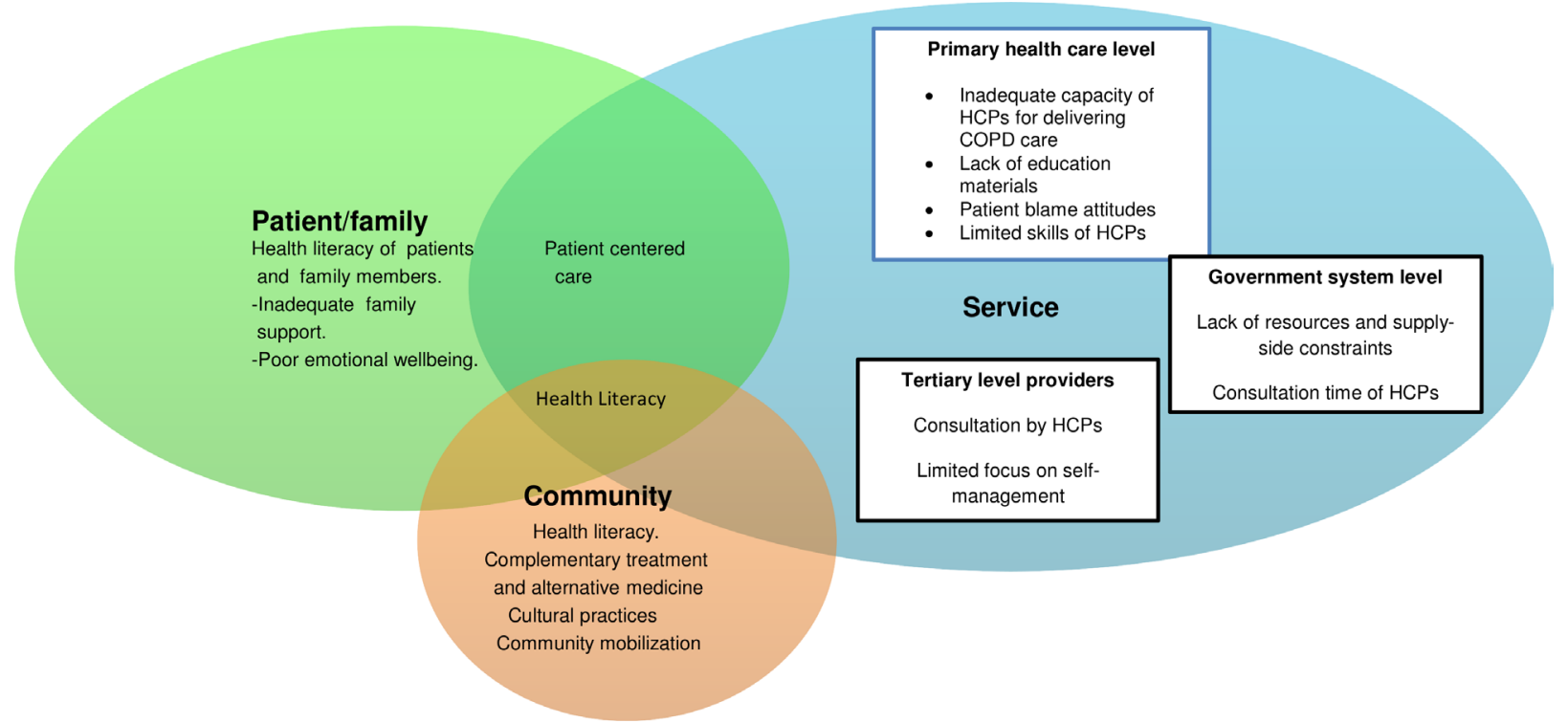

Figure 1 Conceptual framework derived from qualitative findings. COPD, chronic obstructive pulmonary disease; HCP, healthcare provider.

Participants gave examples of factors contributing to inadequate support includes the 'business' of caregivers, the strength of emotional connection (attenuated by distance or by absence of family members), differences in expectations of family and patients, poverty and health literacy. In one family situation, the son travelled for work, and the daughter-in-law was not from Nepal (from India). The mother-in-law felt that she was a burden on the daughter-in-law with whom she did not have a strong emotional connection. Therefore, the mother-in-law reported that she would only receive food when she had completed household chores. One participant with COPD, residing with eight family members mentioned that she received good care because there were a number of carers available in the family. She was supported in daily activities as one family member was always available to look after her.

Family support was sometimes counterproductive. For example, one woman living with COPD mentioned that her son purchased self-prescribed medicines (based on samples of medicine collected from other people with COPD in the community). This meant that the quality and appropriateness of her medications were compromised.

Health literacy: understanding of the disease, medications, health services and prognosis

In this study, low health literacy was defined as an inadequate or incorrect understanding of the disease, medications, lack of information on the healthcare facility and self-management practices by the people with COPD.

\section{Understanding the cause of disease}

Most participants attributed their COPD to a lack of energy, cold temperature, stale food or childhood pneumonia. Most participants from the Madeshi community perceived COPD to be communicable disease and stated that the COPD could be easily transferred by sleeping in a common room. Some people with COPD had misconceptions that cough was contagious similar to that of tuberculosis. A few participants who had a correct understanding of the cause of COPD mentioned that private doctors were the source of their information.

\section{Information on medications}

Half of the participants interviewed had no understanding of the mechanism of action of the medicine that they were taking or its side effects. Some participants believed that the doctors' role was confined to disease diagnosis and treatment and were not aware that doctors should provide information about prescribed medicines. The participants indicated that the doctors did not provide them with any information, such as the role and potential side effects of the medicines that were prescribed. Family members of most people with COPD provided selfprescribed medicines without knowing the mechanism of action of their medicines.

One person who had both hypertension and diabetes was not aware that she should take medicines for all conditions or just for one of them. Furthermore, many participants revealed that they sought medicines for COPD directly from local pharmacies and unregistered HCPs.

\section{Hopes of being cured}

Half of the interviewees with COPD had a belief that COPD was curable. Those participants were involved in doctor shopping (seeing multiple HCPs as new patients). None of the participants was informed by their practitioners that COPD was incurable and that the conditions required long-term management.

Poor emotional well-being

The majority of the people with COPD felt emotionally unstable. They expressed suicidal thoughts, anxiety and fear 
Table 3 Verbatim supporting each theme and subtheme

\begin{tabular}{|c|c|c|c|}
\hline Themes & Subthemes & $\begin{array}{l}\text { Categories under } \\
\text { subthemes }\end{array}$ & Verbatim \\
\hline $\begin{array}{l}\text { People with COPD } \\
\text { and family level } \\
\text { facilitators and } \\
\text { barriers }\end{array}$ & Family support & & $\begin{array}{l}\text { One patient said: } \\
\text { "You are able to see me today just because of my supportive family. } \\
\text { If anyone does wrong in the family, there is another member to } \\
\text { watch them. Overall, all family members are very responsible, and } \\
\text { they do take care of much than me". (IDI: F60-65Y) } \\
\text { One of the participants felt unsupported-who would only provide } \\
\text { food if certain conditions were met. She expressed her voice- } \\
\text { "She (daughter-in-law) often tells me that I am doing drama } \\
\text { (pretending to have disease symptoms). She (daughter-in-law) } \\
\text { say-If I get support from you (....) you will get food else I don't } \\
\text { have time to cook food for you". (IDI: F60-65Y) } \\
\text { One patient expressed the expectation as: } \\
\text { "I think family (son/daughter-in-law) is the first who should look after } \\
\text { us (COPD patients) for medicines, emotional support (listen to our } \\
\text { feelings and concerns). I think I am a burden for them. If I was their } \\
\text { children, I would take care of their conditions with high priority (....) } \\
\text { every support (visit to doctor, medicines, food) but they are not } \\
\text { doing so". (IDI: F50-55Y) } \\
\text { One patient reflected her support as- "My son is very supportive. } \\
\text { Whatever medicine I ask (showing the tablets sample), he gets it to } \\
\text { me from the market". (IDI: F50-55Y) } \\
\text { The above quote suggests that family support was in part } \\
\text { determined by the level of information about the disease among } \\
\text { the family members of the patients. }\end{array}$ \\
\hline
\end{tabular}

Health literacy: understanding of the disease, medications, health services and prognosis
Understanding the cause of disease

A woman with COPD for $>5$ years shared her understanding of a disease that she got from a doctor as "I got to know about the cause from a doctor whom I visited in India (Purnia, Bihar). He (the doctor) said to me, and it's due to a lack of energy and cold temperature". (IDI: F50-55Y)

One participant expressed her experience as "I feared to sleep with my children because it (COPD) will transfer to them, so I sleep alone in the next room". (IDI: F50-55Y)

One participant shared her experience of what made her quit smoking.

"The doctor whom I visited was excellent, and he tried his best to make me understand the disease and linkage of tobacco to my condition. Despite this, I was unable to understand either Nepali or Hindi, but, he found some way for me. (Patient laugh) He explained to me by demonstrating by puffing cigarette (moving fingers at his mouth like the smokers) and indicated it causes difficulty in breathing (by touching chest). He was an excellent doctor that I ever visited". (IDI: F60-65Y)

This had an influence on the participant who subsequently stopped smoking.

Information on medications

One patient expressed her view as "taking multiple medications (allopathic, ayurvedic and homeopathic) at the same time will have a dynamic cumulative effect to cure the disease". (IDI: F60-65Y) The interviewer then asked who got you the medicines. And from where? Patients replied- "My son got it from medical shops. He (son) is very supportive (....) and gets me whatever I ask for". One male patient said:

"I have three diseases (COPD, Hypertension, and Diabetes) but, I do not know either I should take medicine for all disease on a daily basis. To have all the medicines at the same time is really worrisome for me". (IDI: M50-55Y)

Hopes of being cured One of the patients said - "I took medicines with many doctors from Nepal and India but still the condition is the same. Now, I believe there is no medicine discovered for this disease". (IDI: F6065Y) 
Table 3 Continued

\begin{tabular}{|c|c|c|c|}
\hline Themes & Subthemes & $\begin{array}{l}\text { Categories under } \\
\text { subthemes }\end{array}$ & Verbatim \\
\hline & $\begin{array}{l}\text { Poor emotional } \\
\text { well-being }\end{array}$ & & $\begin{array}{l}\text { One female patient said: } \\
\text { "I make plans for my life, but suddenly it (Breathlessness condition, } \\
\text { COPD) come in my way. It (COPD) does not allow me to do } \\
\text { anything. It (COPD) always destroys my vision. This can kill me at } \\
\text { any time (COPD).... am afraid". (IDI: F50-55) } \\
\text { Another female patient expressed her pain as - "I am fed off from } \\
\text { this life, struggling with pain given by this condition. Nowadays, I } \\
\text { like to kill myself because I am not able to find a way for my life". } \\
\text { (IDI: F50-55) } \\
\text { One of the participants said- "I believe motivation and support } \\
\text { from the family are the biggest factors for bringing change in a } \\
\text { person's life and behavior" (IDI: M70-75Y) }\end{array}$ \\
\hline
\end{tabular}

Community-level facilitators and barriers
Complementary and alternative treatment, driven by social network

\section{One patient said:}

"I often use these medicines (Basil leaf and turmeric powder) for improving my conditions because it is easily available. Sometimes it works for decreasing cough but not always". (IDI: F60-65Y) Another patient expressed her view as:

"One person near to my village said to me that he has the medicine for a complete cure for this disease. He provided me with a paste, smelling like ginger and garlic just for Nrs. 100 (0.95 USD). He said, by eating this (paste) thrice a day for a month (three spoon/day) you will get rid of this disease completely. Unfortunately, after eating that (paste), I experienced many side effects involving severe heat production in the body, migraine, and weakness and, eventually, I stopped taking it". (IDI: F70-75Y)

Similarly, another patient said - "I visited Shaman (Dhami: who exercises evil spirits and sickness from the sick body) after the diagnosis of this disease (COPD). He (Shaman) provided me with a paste (tobacco and cloves, which I was not aware of) and told me to eat by putting in Betel leaves for six months. After consuming that for a week, my conditions got very worse, and I dumped those all (paste) and started seeking treatment from a doctor". (IDI: F7580Y)

Community engagement

A FCHV said, "Leave about the uneducated one, most educated people are unaware of this disease and its risk factor". (IDI: F40-45) A HCP highlighted the importance of FCHV in the management of COPD conditions, as illustrated in the following quote "FCHV can play an important role in improving self-management practices among COPD patients. They know patients in their locality, and they can change their behavior very easily. I mean, just involving health professionals is not a solution for management of the chronic disease; the integrated approach is needed". (IDI: M3040)

FCHV added-" In our culture (Tharu and Madhesi community), particularly daughters visit their parents with sweets, curds, bananas, meat items. Factually, they (daughters) don't care about the conditions of parents. I think there is a need for education about the foods for the patients of this disease, which is not happening at all". (IDI: F40-45)

A doctor said:

"Women from Hindu faith practice fast (for example, Jitiya, Chhath, etc) as a part of their culture and traditions for the good of their family members. They have a firm belief in fast, during which they do not take water, food, or medicine". (IDI: M30-35Y)

Service level facilitators and

Boundaries to Patients' views 
Table 3 Continued

\begin{tabular}{|c|c|c|c|}
\hline Themes & Subthemes & $\begin{array}{l}\text { Categories under } \\
\text { subthemes }\end{array}$ & Verbatim \\
\hline & & $\begin{array}{l}\text { Patients' demands } \\
\text { of doctor time and } \\
\text { attention }\end{array}$ & $\begin{array}{l}\text { One patient said: } \\
\text { "Doctor does not pay attention to our voice at all. They (doctors) } \\
\text { just pretend to listen but they do not. Because the doctor whom I } \\
\text { visit never respond to my query. He just say... Yes... Yes... all will be } \\
\text { fine....and......That's it all". (IDI: M75-80) } \\
\text { Another participant reflected a lack of engagement by the doctor: } \\
\text { "When I went to the doctor, and I shared my health problems. } \\
\text { He did not listen to my problems at all. He just took my report } \\
\text { (spirometry) and started writing medicines". (IDI: M70-75Y) } \\
\text { One patient shared her experience with information about physical } \\
\text { activity. "He (the doctor) said to me to do exercise when you felt } \\
\text { comfortable(...) Its good for health. I do not know what exercise I } \\
\text { should do?" (IDI: F50-55Y) }\end{array}$ \\
\hline
\end{tabular}

Limited confidence

of patients in communication with doctor
One patient who noted the importance of family member involvement in the communication with the doctor stating, "I visited the doctor with my son, and he speaks to the doctor in the language that doctors used (Nepali). He (son) reflected my concerns to the doctor". (IDI: F50-55Y)

A participant who cited lack of confidence is the barrier to communicate with doctors said, "When I see a doctor, I lost myself and cannot tell my health problem that I was supposed to". (IDI: F50-55Y)

Limited skills and expertise of the doctors in behavioural change

With regard to physical activity for patients with COPD, one patient said - "First of all I do not know the steps of exercise, and the next thing is that how exercise will benefit the COPD patients like me. If I were explained both I would have practiced, but I was just told to do exercise, so I ignored it". (IDI: F50-55Y)

Another participant said, "Medicines is better right, why do we need to do exercise?" (IDI: F50-55Y)

An example of how a male participant felt for giving up smoking is presented below:

"Doctors told me-don't smoke, and you will be okay with time. But still, I am not able to find a way to give it (cigarette) up". (IDI: M50$55 Y)$

Frustration with doctors

A woman who sought healthcare said:

".... I went to Kathmandu (Bir Hospital, Nepal) for the first time. $\mathrm{He}$ (the doctor) checked my health and provided with medicines. I took that for six months but no improvement. I and he (the doctor) gave the medicine by doing some lab and physical check-up.... No improvement...After that, I went to Darbhanga (India), and the doctor said-these symptoms are because of weakness and he (doctor) gave me many medicines, but they don't work. Then, after a year I visited a doctor in Biratnagar (Private hospital, Nepal) and I took his medicine for one year and then he (the doctor) said-this seems to be chronic respiratory disease and I (the doctor) am not the specialist. He recommended me to visit BPKIHS, Dharan (Tertiary level hospital with a medical college, Nepal), where I was diagnosed with this disease. Why do they prescribe medicine if they (the doctor) could not diagnose the disease? This is very frustrating". (IDI: F50-55Y)

A man with COPD reflected,

".... I don't have information that a respiratory doctor checks this disease (COPD). I visited many doctors (five doctors) in the process of diagnosis of COPD. If I had the right information, I would not have to suffer much just for diagnosis. It (diagnosis with many doctors) put me in debt". (IDI: M75-80Y) 
Table 3 Continued

\begin{tabular}{lll}
\hline Themes & Subthemes & $\begin{array}{l}\text { Categories under } \\
\text { subthemes }\end{array}$ \\
\hline
\end{tabular}

Limited skills of healthcare providers

\section{Verbatim}

A doctor said:

"I am here for the peoples but, I don't have exposure in managing COPD". (IDI: M30-35Y)

Same doctor said, "I have not heard of any special breathing exercise for COPD patients. Well, physical activity does have benefits for COPD patients of lower age but not for older age patients". (IDI: M30-35Y)

One HCP stated that:

"Patients need information on conditions and medications, motivation, and support for adopting lifestyle behaviors. This is unfortunate that we don't practice because of the time factor". (IDI: M30-40)

Adding to this, a nurse said- "There is a need for improvement of communication between patients and service provider without which behaviour change is critically difficult. HCPs need to develop skills to respond to patients in such a way that their (patients) situation should de-escalate and patients get ready to adopt healthy behavior". (IDI: F25-30)

Patients limit in self- A nurse working at peripheral health system shared her view by management stating that:

"In this rural setting, very few people know about this (COPD) disease and its risk factor. More importantly, people lack information about the right health center where they can get the right services for a respiratory problem". (IDI: F25-30)

One HCP said- "we (peripheral health facilities) have nothing on COPD. I do not know if centre (Department of Health Services, Ministry of Health) have materials for educating about COPD". (IDI: M30-40)

Patient blame

One HCP stated that:

"Despite advising the patient to give up cigarettes, but they don't listen at all. I (HP) feel they (patients) don't want to change". (IDI: M30-40)

\section{Poor family support One HCP said:}

"Through our social system is strong but people with chronic disease like COPD are not receiving adequate support from the family members. There should be an educational program focusing the family level to create enabling environment for COPD people". (IDI: M30-40)

A FCHV said:

"Patients belonging to low income family, particularly Dalits and Indigenous community usually do not get enough family support or care. They (family members) do not have enough money to take patients to doctors and purchase good food (nutritious food). In some families people of chronic disease are subjected to abuse". (IDI: F40-45)

Quality of care: limited service at the health post (HP) and primary healthcare centre (PHCC)
A middle-aged woman said:

"Health staff at the HP/PHC provided this (Salbutamol) free medicine to the person who comes from power (political background people of their relatives) or who are educated. One nurse (Pahadni-a slag used for people of different origin) gave me when I said I am the sister of a local leader". (IDI: F70-75Y) A man with COPD for more than $>3$ years said:

"I heard that services at government health facilities (HP/PHCC) are of no use. They (health professionals) always say patients they have not received medicine from the top level. So, I have never been there better I go to private doctors". (IDI: M70-75Y)

When researcher asked how do you see the quality of care at HP/ PHC? Patient replied - "If the diseases cannot be treated at the local level means they is no point of rating the quality. Therefore, I would say there is no quality at all". (IDI: M70-75Y) 
Table 3 Continued

\begin{tabular}{|c|c|c|c|}
\hline Themes & Subthemes & $\begin{array}{l}\text { Categories under } \\
\text { subthemes }\end{array}$ & Verbatim \\
\hline & $\begin{array}{l}\text { Healthcare system- } \\
\text { level gaps }\end{array}$ & & $\begin{array}{l}\text { In this line, a nurse expressed herself as: } \\
\text { "Infrastructure is basic for delivering care at PHCC level. We have } \\
\text { building (PHCC/HP Physical infrastructure). We (health facility } \\
\text { where she was working) don't have an oxygen cylinder or nebulizer } \\
\text { that is essentially required at PHC or nor the relevant medicines } \\
\text { for COPD patients. See (pointing to X-ray and ECG room by nurse) } \\
\text { there are X-ray and ECG, but no one knows how to operate?" (IDI: } \\
\text { F25-30) } \\
\text { A doctor said- "We (health professionals at peripheral health } \\
\text { system) always send the request in advance to the district, but } \\
\text { unfortunately medicines never reach in time. This part is most } \\
\text { important but is widely ignored by our system". (IDI: M30-35Y) } \\
\text { Moreover, a doctor added "we (local level health system) do not } \\
\text { have financial resources to implement any program for COPD". (IDI: } \\
\text { M30-35Y) }\end{array}$ \\
\hline
\end{tabular}

COPD, chronic obstructive pulmonary disease; PHC, primary healthcare; PHCC, primary healthcare centre.

of sudden death due to inability to breathe. Anxiety and fear were a major limiting factor that prevented them from taking care of their condition. The majority felt that family members were not able to understand their emotions.

\section{Community-level facilitators and barriers}

Complementary and alternative treatment, driven by social network

In regional areas of Nepal, complementary and alternative treatment involves the use of herbs, plant materials, ayurvedic medicines, traditional medicines, homeopathic medicines and remedies based on knowledge gained across generations. The use of such medications is not determined by spiritual beliefs but primarily by ease of access. In the interviews, we found that at the onset of their disease, people with COPD and their family members often first collected the information on complementary and alternative treatment, because of their easy availability and low cost.

Nearly half of the people with COPD (most Madeshi and few Indigenous) indicated that they had used complementary medicines at some point before or after the diagnosis of the disease. Participants discussed alternative therapies when asked about how they manage their condition. Many participants had received treatment from a Shaman (who marketed themselves as 'self-doctors') and this was facilitated by other community members. The interviewer also observed that community members attempted to encourage patients to use complementary medicines by providing examples of similar patients who found relief using such medication. Participants described the different types of complementary medicines used that included holy basil leaves, crude herbal extract (Jadibutti), turmeric powder, a smoothie of curd and bitten rice, molasses, tobacco and cloves paste and ginger and garlic paste. Most of the participants reported that using complementary medicine had worsened their symptoms. Thus, they stopped taking them.
Community engagement

Female community health volunteer (FCHV) and a medical participant felt that community dwellers could play a vital role in creating awareness about the disease and risk factors at the community level. FCHVs were cited as an enabler by all HCPs. All HCPs saw FCHVs as the backbone of community-level health programmes in Nepal and felt that involvement of FCHV could help to improve health literacy and modify lifestyle behaviours. All HCPs said a community-level health literacy programme could enable behaviour change both among the people at risk and people with long-term conditions like COPD.

Cultural practices such as fasting and serving 'cold' foods to people with COPD were cited as impeding factors for self-management. An FCHV and a medical officer expressed the need to change some cultural practices in consultation with local leaders and community members. Not taking medicines throughout the fasting period was one of the reasons for poor medication adherence among Hindu and Islamic communities.

\section{Service level facilitators and barriers}

Boundaries to patient-centred care

The active engagement of patients in their selfmanagement is often impeded by factors that exist at both patient and HCPs level. Perspectives of both patient and HCPs are discussed here.

\section{Perspectives of people with COPD}

Patients' demands of doctor time and attention

Half of interviewees with COPD indicated that their doctors paid insufficient attention to them during their hospital (public/private tertiary level) visit. Their main concerns were that the doctors did not listen, ignored their questions and used medical terms which they could not understand. Few participants mentioned that they received information about their disease or the physical activity necessary for 
minimal disease management. None mentioned receiving motivational support for lifestyle behaviour change.

Most of the participants complained that the amount of time provided by doctors with patients was not sufficient to share their health concerns. During postinterview conversation, many patients felt that doctors should listen and respond to their health concerns before prescribing medicines.

\section{Limited confidence of patients in communication with doctor}

Most of the participants had poor confidence levels and language was a major barrier to expressing their concerns with the doctors. A few people with COPD who visited a doctor with their family members reported good communication with the doctor.

\section{Limited skills and expertise of the doctors in behavioural change}

Patients reported that the doctor's scope of practice was limited to prescribing medicines and was not sufficiently focused on behavioural management components (education on disease and prevention, quitting smoking, motivation, exercise training). This problem was raised by most of the people with COPD. Only a few reported receiving the information on exercise from their doctor, and none of them was able to describe the type of exercise recommended by their doctor.

Similarly, of those people with COPD who received information on quitting smoking, only a few reported having quit. Those who had quit cited motivational support and understanding the consequences of smoking. Those people who were unable to quit reported lack of willpower as the primary reason.

\section{Frustration with doctors}

Most respondents were frustrated with their doctors because of the length of time taken to diagnose their condition (5-8 years) despite visiting the doctor regularly and the number of medicines prescribed without proper diagnosis.

\section{Perspective of peripheral government healthcare providers}

Limited skills of healthcare providers

All HCPs cited limited skills in COPD diagnosis and treatment, inability to motivate and support patients and insufficient communication between health professionals and patients as a barrier in supporting self-management among patients with COPD. One nurse from one of the peripheral health centres had experience in managing COPD at a private hospital where she worked prior to joining a job in the government sector. A medical participant working in PHCC reported that despite wanting to help patients with COPD, he did not have adequate clinical skills. He also stated that chronic disease management should focus on comorbidity rather than just considering any single chronic condition.

The medical participant working in PHCC was familiar with the case vignette and goal setting approach for quitting smoking but was unaware of the benefits of physical activity or breathing exercises for patients with COPD. The interviewer noted that the medical participant was willing to make a change, but he had been unable to find ways to help the patients with COPD. All HCPs cited insufficient consultation time and a lack of skill in supporting behaviour change as a limitation at the primary care level.

\section{Patients limit in self-management}

All HCPs highlighted factors such as poor health literacy (lack of information on the disease and on available services), language barriers, delay in health-seeking and inflexible attitude of patients to adopt healthy lifestyle as barriers for poor self-management among patients with COPD.

\section{Patient blame attitude}

During interviews, two health professionals blamed the patients. When probed for the reason, one cited 'negative patient attitude', for example, patients who felt they already knew everything. Another stated that patients do not listen to the HCPs advice, for example, quit smoking. On probing by the researcher, HCPs reported that lack of rapport and trust between patients and health professionals contributed to their attitudes.

\section{Poor family support}

All HCPs reported that people with COPD were not getting the support from families that they required to manage the condition. The possible reasons behind this poor family support included: low economic status of family members preventing them from being absent from their job/work; lack of understanding of the role of family members could play in the management of their conditions and, sometimes, family level disputes. One HCP mentioned that educated families do not have these issues and they take appropriate care of the people with COPD. All HCPs highlighted the need of family level support in self-management of the condition.

\section{Quality of care: limited service at the HP and PHCC}

During the field observation by the lead author, it was noted that the PHCCs did not have any specific guidelines for COPD diagnosis, treatment or management. PHCCs and HPs were observed providing 'salbutamol' for any patients with respiratory difficulty. However, out of 10 people with COPD, only 3 reported that they visited the HP/PHCC for salbutamol. No participants reported being satisfied with services provided by the local level cadre of the government health system. The reported dissatisfaction was the rude behaviour of healthcare professionals and the unavailability of salbutamol at their time of the visit to the health centre.

\section{Healthcare system-level gaps}

All HCPs reported that infrastructural constraints such as unavailability of treatment or management guidelines for COPD at PHCC level, education materials for COPD, limited equipment and medicine supplies and inadequate consultation time were barriers at the system level. These HCPs specifically mentioned the lack of demonstration 
materials such as a flip chart to build COPD awareness, lack of or unused medical equipment (X-ray, oxygen cylinder), unavailability of different medicines (including inhalers) and the timely or limited supply of available listed medication (eg, salbutamol).

Two medical participants cited the lack of sufficient funding from the local level government for managing COPD and other chronic conditions. They also reported a lack of consultation with HCPs prior to budget allocation at the local level.

\section{DISCUSSION}

This study identified the facilitators and barriers for selfmanagement operating at the people with COPD/family, community and service delivery levels.

\section{Patient/family level facilitators and barriers}

Our study found that low health literacy was a barrier to people with COPD engaging in self-management practices. People with COPD had poor understanding of the disease as well as limited information on healthcare facilities and medications. Half of the patients interviewed believed that COPD was contagious and curable. Poor health literacy among the patients can be attributed to several underlying factors, including lack of formal education and incorrect information on the disease. Consistent with findings, earlier research has shown that patients had similar beliefs that COPD was contagious ${ }^{20} 21$ and curable,$^{22}$ and lacked information on available health services. ${ }^{22}$ In support to our findings, other studies from Nepal have described patients with low health literacy seeking medications directly from local pharmacies without prescriptions ${ }^{23}$ and non-formal doctors without formal diagnosis. ${ }^{2324}$ Earlier evidence has shown that poor health literacy impedes the patient's ability to seek and understand the information required for selfmanagement of COPD. ${ }^{925}$ The roles and health literacy of family members regarding COPD was not directly explored (as we did not interview family members). However, participants reported receiving information, advice and even medications from family members and in some cases this put the participants at risk. Supporting this, we noted that some of the people with COPD were on self-prescribed medicines provided by their family members, which could be because of lack of information about the consequences of those medicines among the family members.

In the Nepalese context, where people believe that families take responsibility for caring for people with COPD, the lack of family support was surprising. These values seemed not to be applied because, people with COPD were considered to be a burden for family members in terms of workload and cost. As a result, the people with COPD experience adjustment problems ${ }^{26}$ in the family. This is likely to strain the emotional connection between patients and family members, which in turn add stress and anxiety to patients. Our study revealed that negative emotions experienced by people with COPD were one of the barriers to self-management practices and this was in line with previous studies. ${ }^{27} 28$ Furthermore, the lack of information on disease diagnosis and treatment leads to doctor shopping behaviour (DSB), where people consult number of practitioners of different specialties at different healthcare facilities in a hope to get complete cure for a disease. DSB is also caused by lack of satisfaction with local HCPs and available healthcare services.

Emphasis needs to be placed on tailoring behavioural or psychological activities that target the family-patient dyad, which may help the people with COPD to adopt healthy lifestyle and improve their psychological wellbeing. ${ }^{29}$ Interventions that included family involvement in Self-management practices (SMPs) have been shown to increase adherence to medications, exercise and smoking cessation. ${ }^{30-32}$

\section{Community-level facilitators and barriers}

Many patients in this study reported using complementary medicines because of influence of family or other community members without knowing the consequences or benefits of such medicine. While some complementary medicines may be harmless, others may lead to delay in formal diagnosis and treatment. Previous Nepalese studies have documented the self or non-professional (community members or shaman) guided use of complementary medicines. ${ }^{33} 34$

Some cultural practices such as fasting (particularly among women) or the practice of feeding cold, sweet and salty food to people with COPD were commonly reported at the community level. In this cultural context, these practices were based on strong religious or social beliefs. These practices are not documented in Nepalese setting. However, study from Denmark and Australia has documented fasting as cultural practice among the Islamic community that impeded medical compliance among patients with chronic disease ${ }^{35}{ }^{36}$ Limited health literacy at the community level may contribute to these cultural practices and can be improved by interventions involving community groups, religious leaders and local political leaders. Also, in this context, mobilisation of community health workers (FCHV) could provide health information and transferable skills such as control of indoor air pollution, motivating skills, locally accepted yoga and meditation practices for respiratory health, etc.

\section{Service level facilitators and barriers}

Healthcare delivery in a rural setting is largely met by PHCCs and HPs. The PHC system should carry out screening and management of mild COPD cases supported by referral pathways with the public tertiary health facility for acute or severe cases. However, no services for COPD were available at the time of the survey. In this context, the peripheral health system lacked trained human resources to manage COPD, necessary medical equipment and education materials to provide self-management support to people with COPD. ${ }^{15} 2137$ Health services for COPD were 
limited to public and private tertiary level health facilities in the studied localities in Nepal. The availability of health services at local level for COPD would help the patients in getting care at the right time and early involvement in self-management.

There has been increasing interest in patient-centred care around the world. However in Nepal, this is impaired by short consultation times and limited skills of practitioners in behavioural management. These barriers were identified in the previous studies from Nepal and other settings ${ }^{38-41}$ and could negatively affect the patient's ability to communicate and to understand the information effectively, resulting in poor patient's engagement in self-management. ${ }^{42-45}$ Similarly, there was inadequate motivational support from the provider side to encourage patients in shared decisionmaking, health-related behaviours and self-management. A study ${ }^{46}$ from Nepal found that providers did not pay sufficient attention to encouraging patients to manage the lifestyle behaviours. Primary HCPs were willing to support and tailor the care to address the patient's needs, but they were not able to find ways to support patients. Therefore, Nepalese providers in the studied area need training in disease diagnosis and management and motivational interviewing for behaviour change.

\section{Policy implications}

The goal of the National Health Policy 2018 in Nepal was to strengthen the public health system and accelerate progress towards universal health coverage. However, access to primary care for COPD was impaired by the limited availability of facilities and resources. Developing a standard operating protocol for disease diagnosis, treatment and referral for PHC/PHCC in the study setting could be a step forward.

Our findings highlighted the need to design an integrated model of care with multilevel strategies that could tackle the barriers that hinder the self-management of COPD including the low levels of health literacy in the study area of rural Nepal. People with COPD need to be empowered to engage in self-management of their conditions. Both these strategies require coordinated effort from different levels. We suggest the need of future work to validate these findings over a wider geography of Nepal.

\section{Limitations}

The generalisation of the findings to other locations in Nepal needs to be made with caution. Our sample was relatively small and was confined to two local rural municipalities. Moreover, purposive selection of the patients and HCPs based on their ability to share information may have biassed the responses.

\section{CONCLUSIONS}

Self-management of COPD was affected by facilitators and barriers at three different levels (people with COPD and family, community and service level). These need to be addressed through an integrated model of care for people with COPD. Our analysis revealed that poor family level support, poor health literacy, low patient empowerment and lack of services for COPD at the local level were the most important factors needing to be addressed to improve self-management practices among patients with COPD in studied rural setting of Nepal.

\section{Author affiliations}

${ }^{1}$ Reserach and Evaluation, Forum for Health Reserach and Development, Dharan, Nepal

${ }^{2}$ Centre for Primary Health Care and Equity, University of New South Wales, Sydney, New South Wales, Australia

${ }^{3}$ School of Health and Society, University of Wollongong, Wollongong, New South Wales, Australia

${ }^{4}$ School of Public Health, Patan Academy of Health Sciences, Lalitpur, Nepal ${ }^{5}$ Ministry of Health and Population, Government of Nepal, Kathmandu, Province III, Nepal

${ }^{6}$ Department of Pulmonary, Critical Care and Sleep Medicine, B.P. Koirala Institute of Health Sciences (BPKIHS), Dharan, Nepal

Twitter Uday Narayan Yadav @UNYadav

Acknowledgements The authors would like to thank the local-level authorities of the government of Nepal for their support in providing us with the list of patients with COPD. The authors would like to thank Mr. Gajendra Yadav (Health Co-ordinator of Gadhi Rural Municipality), Mr. Dinesh Chaudhary (Barju Rural Municipality) for providing the support in reaching the patients and, Mr. Krishna Yadav and Nitesh Mandal for their tireless work in field management. The authors would also like to thank the patients with COPD and healthcare providers who participated in the study, without whom this study would not have been successful.UNY is receipt of UNSW International Postgraduate Scholarship and CPHCE Top-up Scholarship for pursuing $\mathrm{PhD}$.

Contributors UNY conceived and conducted the fieldwork and wrote the first version of this manuscript as a PhD student under the supervision of MFH, JL, $\mathrm{HH}$, $\mathrm{KPB}, \mathrm{SD}$ and NB. UNY, JL and MFH participated in the data analysis. All authors read and gave their approval to the final version of this manuscript submitted for publication.

Funding This fieldwork was supported by the Medibank International Fieldwork Grant.

Disclaimer The funding body had no role in the study.

Competing interests None declared.

Patient consent for publication Not required.

Ethics approval Ethics approval was obtained from Human Research Ethics Committee (HREC) of University of New South Wales (UNSW), Sydney, Australia (HC180502), and the Nepal Health Research Council (Reg. no. 495). All the participants completed and signed an informed consent form.

Provenance and peer review Not commissioned; externally peer reviewed.

Data availability statement Data sharing not applicable as no datasets generated and/or analysed for this study. The de-identified data are available on request from the corresponding author.

Open access This is an open access article distributed in accordance with the Creative Commons Attribution Non Commercial (CC BY-NC 4.0) license, which permits others to distribute, remix, adapt, build upon this work non-commercially, and license their derivative works on different terms, provided the original work is properly cited, appropriate credit is given, any changes made indicated, and the use is non-commercial. See: http://creativecommons.org/licenses/by-nc/4.0/.

\section{ORCID iDs}

Uday Narayan Yadav http://orcid.org/0000-0002-6626-1604

Mark Fort Harris http://orcid.org/0000-0002-0705-8913

\section{REFERENCES}

1 Singh D, Agusti A, Anzueto A, et al. Global strategy for the diagnosis, management, and prevention of chronic obstructive lung disease: the gold science Committee report 2019. Eur Respir J 2019;53:1900164.

2 Guarascio AJ, Ray SM, Finch CK, et al. The clinical and economic burden of chronic obstructive pulmonary disease in the USA. Clinicoecon Outcomes Res 2013;5:235-45. 
3 World health organisation. Chronic respiratory diseases [English]. Available: https://www.who.int/respiratory/copd/World_Health Statistics_2008/en/

4 Mills A. Health care systems in low- and middle-income countries. $N$ Engl J Med 2014;370:552-7.

5 Nepal Health Research Council, Government of Nepal. Population based prevalence of selected non-communicable diseases in Nepal. Kathmandu, Nepal: Nepal Health Research Council, Government of Nepal, 2019.

6 Kaptein AA, Fischer MJ, Scharloo M. Self-Management in patients with COPD: theoretical context, content, outcomes, and integration into clinical care. Int J Chron Obstruct Pulmon Dis 2014;9:907-17.

7 Wagner EH, Groves T. Care for chronic diseases. BMJ 2002;325:913-4.

8 Effing TW, Bourbeau J, Vercoulen J, et al. Self-Management programmes for COPD: moving forward. Chron Respir Dis 2012;9:27-35.

9 Yadav UN, Hosseinzadeh H, Lloyd J, et al. How health literacy and patient activation play their own unique role in self-management of chronic obstructive pulmonary disease (COPD)? Chron Respir Dis 2019;16:1479973118816418.

10 Jerant AF, von Friederichs-Fitzwater MM, Moore M. Patients' perceived barriers to active self-management of chronic conditions. Patient Educ Couns 2005;57:300-7.

11 Johnston KN, Young M, Grimmer-Somers KA, et al. Why are some evidence-based care recommendations in chronic obstructive pulmonary disease better implemented than others? perspectives of medical practitioners. Int J Chron Obstruct Pulmon Dis 2011:6:659-67.

12 Yadav UN, Hosseinzadeh H, Baral KP. Self-Management and patient activation in COPD patients: an evidence summary of randomized controlled trials. Clin Epidemiol Glob Health 2018;6:148-54.

13 Liddy C, Blazkho V, Mill K. Challenges of self-management when living with multiple chronic conditions: systematic review of the qualitative literature. Can Fam Physician 2014;60:1123-33.

14 Russell S, Ogunbayo OJ, Newham JJ, et al. Qualitative systematic review of barriers and facilitators to self-management of chronic obstructive pulmonary disease: views of patients and healthcare professionals. NPJ Prim Care Respir Med 2018;28:2.

15 Ogunbayo OJ, Russell S, Newham JJ, et al. Understanding the factors affecting self-management of COPD from the perspectives of healthcare practitioners: a qualitative study. NPJ Prim Care Respir Med 2017;27:54.

16 Halding A-G, Aarsheim El, Dolmen NM, et al. Copd transitions in health and self-management: service users' experiences from everyday life. Int J Chron Obstruct Pulmon Dis 2018;13:2075-88.

17 Braun V, Clarke V. Using thematic analysis in psychology. Qual Res Psychol 2006;3:77-101.

18 Scotland J. Exploring the philosophical underpinnings of research: relating ontology and Epistemology to the methodology and methods of the scientific, interpretive, and critical research paradigms. ELT 2012;5:9-16.

19 Bronfenbrenner U. Toward an experimental ecology of human development. Am Psychol 1977;32:513-31.

20 Wortz K, Cade A, Menard JR, et al. A qualitative study of patients' goals and expectations for self-management of COPD. Prim Care Respir J 2012;21:384-91.

21 Wong SSL, Abdullah N, Abdullah A, et al. Unmet needs of patients with chronic obstructive pulmonary disease (COPD): a qualitative study on patients and doctors. BMC Fam Pract 2014;15:67.

22 Yang $\mathrm{H}$, Wang $\mathrm{H}$, Du L, et al. Disease knowledge and selfmanagement behavior of COPD patients in China. Medicine 2019;98:e14460.

23 Garha M. Health care in Nepal: an observational perspective. J Nurs Educ Pract 2017;7.

24 Shankar PR, Partha P, Shenoy N. Self-Medication and nondoctor prescription practices in Pokhara Valley, Western Nepal: a questionnaire-based study. BMC Fam Pract 2002;3:17.

25 Kale MS, Federman AD, Krauskopf K, et al. The association of health literacy with illness and medication beliefs among patients with chronic obstructive pulmonary disease. PLoS One 2015;10:e0123937.

26 Yadav UN, Paudel G. Prevalence and associated factors of elder mistreatment: a cross sectional study from urban Nepal. Age Ageing 2016;45:609-13.

27 Bair MJ, Matthias MS, Nyland KA, et al. Barriers and facilitators to chronic pain self-management: a qualitative study of primary care patients with comorbid musculoskeletal pain and depression. Pain Med 2009;10:1280-90.

28 Chen K-H, Chen M-L, Lee S, et al. Self-Management behaviours for patients with chronic obstructive pulmonary disease: a qualitative study. J Adv Nurs 2008;64:595-604.

29 Rosland A-M, Piette JD. Emerging models for mobilizing family support for chronic disease management: a structured review. Chronic IIIn 2010;6:7-21.

30 Mayberry LS, Osborn CY. Family support, medication adherence, and glycemic control among adults with type 2 diabetes. Diabetes Care 2012;35:1239-45.

31 McBride CM, Baucom DH, Peterson BL, et al. Prenatal and postpartum smoking abstinence a partner-assisted approach. Am J Prev Med 2004:27:232-8.

32 Brown HE, Atkin AJ, Panter J, et al. Family-Based interventions to increase physical activity in children: a systematic review, metaanalysis and realist synthesis. Obes Rev 2016;17:345-60.

33 Thorsen RS, Pouliot M. Traditional medicine for the rich and knowledgeable: challenging assumptions about treatment-seeking behaviour in rural and peri-urban Nepal. Health Policy Plan 2016:31:314-24.

34 Sapkota S, Brien J-AE, Aslani P. Nepalese patients' perceptions of treatment modalities for type 2 diabetes. Patient Prefer Adherence 2016;10:1777-86.

35 Mygind A, Kristiansen M, Wittrup I, et al. Patient perspectives on type 2 diabetes and medicine use during Ramadan among Pakistanis in Denmark. Int J Clin Pharm 2013;35:281-8.

36 Almansour HA, Chaar B, Saini B. Perspectives and experiences of patients with type 2 diabetes observing the Ramadan fast. Ethn Health 2018;23:380-96.

37 Young HML, Apps LD, Harrison SL, et al. Important, misunderstood, and challenging: a qualitative study of nurses' and allied health professionals' perceptions of implementing self-management for patients with COPD. Int J Chron Obstruct Pulmon Dis 2015;10:1043-52.

38 Dahal P, Bhattarai B, Adhikari D, et al. Drug use pattern in primary health care facilities of Kaski district, Western Nepal. Sunsari Technical College Journal 2013;1:1-8.

39 Irving G, Neves AL, Dambha-Miller $\mathrm{H}$, et al. International variations in primary care physician consultation time: a systematic review of 67 countries. BMJ Open 2017;7:e017902.

40 Shrestha S, Shrestha A, Koju RP, et al. Barriers and facilitators to treatment among patients with newly diagnosed hypertension in Nepal. Heart Asia 2018;10:e011047.

41 Moore M. What does patient-centred communication mean in Nepal? Med Educ 2008;42:18-26.

42 de Moissac D, Bowen S. Impact of language barriers on quality of care and patient safety for official language minority Francophones in Canada. J Patient Exp 2019;6:24-32.

43 Jacobs B, Ir P, Bigdeli M, et al. Addressing access barriers to health services: an analytical framework for selecting appropriate interventions in low-income Asian countries. Health Policy Plan 2012;27:288-300.

44 Wasserman M, Renfrew MR, Green AR, et al. Identifying and preventing medical errors in patients with limited English proficiency: key findings and tools for the field. J Healthc Qual 2014;36:5-16.

45 Richardson A, Thomas VN, Richardson A. "Reduced to nods and smiles": experiences of professionals caring for people with cancer from black and ethnic minority groups. Eur J Oncol Nurs 2006:10:93-101.

46 Ide N, LoGerfo JP, Karmacharya B. Barriers and facilitators of diabetes services in Nepal: a qualitative evaluation. Health Policy Plan 2018;33:474-82. 